\title{
Motoneuron Transplantation Rescues the Phenotype of SMARD1 (Spinal Muscular Atrophy with Respiratory Distress Type 1)
}

\author{
Stefania Corti, ${ }^{1,2}$ Monica Nizzardo, ${ }^{1}$ Martina Nardini, ${ }^{1}$ Chiara Donadoni, ${ }^{1}$ Sabrina Salani, ${ }^{1}$ Roberto Del Bo, ${ }^{1}$ \\ Dimitra Papadimitriou, ${ }^{1}$ Federica Locatelli, ${ }^{3}$ Nicoletta Mezzina, ${ }^{1}$ Francesca Gianni, ${ }^{1}$ Nereo Bresolin, $, 2,3$ \\ and Giacomo P. Comi ${ }^{1,2}$ \\ ${ }^{1}$ Dino Ferrari Centre, Department of Neurological Sciences, University of Milan, Istituto di Ricovero e Cura a Carattere Scientifico (IRCCS) Foundation \\ Ospedale Maggiore Policlinico, Mangiagalli and Regina Elena, 20122 Milan, Italy, ${ }^{2}$ Centre of Excellence on Neurodegenerative Diseases, University of Milan, \\ 20122 Milan, Italy, and ${ }^{3}$ IRCCS Eugenio Medea, Bosisio Parini, 23842 Lecco, Italy
}

Spinal muscular atrophy with respiratory distress type 1 (SMARD1) is a fatal form of infantile motoneuron disease. There is currently no effective treatment, although motor neuron replacement is a possible therapeutic strategy. We transplanted purified motor neurons into the spinal cord of $n m d$ mice, an animal model of SMARD1. We also administered pharmacological treatment targeting the induction of axonal growth toward skeletal muscle target. At the end stage of the disease, donor-derived motor neurons were detected in the $n m d$ anterior horns, extended axons into the ventral roots, and formed new neuromuscular junctions. These data correlated with improved neuromuscular function and increased life spans. The neuroprotective effect was associated with a reduction in proinflammatory molecules in treated spinal cords. This is the first report that functional restoration of motor units with transplanted motoneurons is feasible in an animal model of a human motoneuron disease, opening up new possibilities for therapeutic intervention.

\section{Introduction}

Spinal muscular atrophy with respiratory distress type 1 (SMARD1; Mendelian Inheritance in Man number 604320) is an autosomal recessive motor neuron disorder that affects infants. The hallmarks of SMARD1 are severe spinal muscular atrophy and diaphragmatic paralysis (Mellins et al., 1974). SMARD1 is caused by mutations in the IGHMBP2 gene, which encodes Ig micro-binding protein 2 (Grohmann et al., 2001, 2003; Kaindl et al., 2008). A splice-site mutation in mouse Ighmbp2 is responsible for spinal muscle atrophy in the neuromuscular degeneration (nmd) mouse, which serves as the animal model of SMARD1 (Cox et al., 1998). The cellular function of the IGHMBP2 protein is not well understood, but it seems to be involved in transcription and pre-mRNA processing (Fukita et al., 1993; Molnar et al., 1997). The IGHMBP2 gene is ubiquitously expressed, and the sequence of events resulting in selective motoneuron vulnerability is unknown (Grohmann et al., 2001, 2004).

Effective treatments for motor neuron diseases including SMARD1 are not currently available. One potential strategy is to replace the damaged neurons using neural stem cells (NSCs) or

Received June 10, 2009; revised July 29, 2009; accepted Aug. 15, 2009.

This work was supported by research grants from the Italian Ministry PRIN 2006 (G.P.C., S.C., and N.B.), Telethon Italy (GGP06043 to G.P.C., S.C., and N.B.), and the Cariplo Foundation (G.P.C.). We thank the "Associazione Amici del Centro Dino Ferrari" for support.

Correspondence should be addressed to Giacomo P. Comi, Department of Neurological Sciences, University of Milan, Istituto di Ricovero e Cura a Carattere Scientifico Foundation 0spedale Maggiore Policlinico, Mangiagalli and Regina Elena, Padiglione Ponti, Via Francesco Sforza 35, 20122 Milan, Italy. E-mail: giacomo.comi@unimi.it.

DOI:10.1523/JNEUROSCI.2734-09.2009

Copyright $\odot 2009$ Society for Neuroscience 0270-6474/09/2911761-11\$15.00/0 motoneurons that have been differentiated from stem cells (Hedlund et al., 2007). Preclinical experiments with transplantation of embryonic stem (ES) cell-derived motoneurons in animal models have demonstrated that grafted motoneurons can survive and become integrated into host spinal cord (Wichterle et al., 2002; Harper et al., 2004; Deshpande et al., 2006). To our knowledge, only one report of the replacement of a motor neuron circuit that also includes neuromuscular junction after ES-derived motor neuron transplantation within the adult mammalian host has been reported using adult rats in which motoneurons are killed by the neuroadapted Sindbis virus (Deshpande et al., 2006).

We have previously described a method to isolate a primitive NSC fraction that is positive for Lewis $\mathrm{X}(\mathrm{LeX}+)$, an extracellular matrix-associated carbohydrate expressed by ES cells and NSCs (Corti et al., 2005). This fraction, transplanted into the spinal cord, can generate new neurons and modify disease progression in SOD1G93A mice, an animal model of amyotrophic lateral sclerosis (ALS) (Corti et al., 2005). In addition, we reported previously that a different fraction of NSCs, $\mathrm{ALDH}^{\text {hi }}$ SSC $^{\text {lo }}$ cells that were isolated on the basis of aldehyde dehydrogenase activity, when transplanted intrathecally into $n m d$ mice delayed disease progression and increased life span (Corti et al., 2006). This was the first experimental investigation to use cell therapy in the $n m d$ mouse model.

In the present study, we investigated the therapeutic potential of differentiated motoneuron transplantation into the spinal cord of $n m d$ mice. First, we devised a method to obtain relatively pure motoneuron cell cultures that could functionally integrate 
in vivo. Second, we evaluated the effect of motoneuron transplantation on the SMARD1 disease phenotype in nmd mice, both alone and in combination with pharmacological treatment targeting the induction of axonal growth. To our knowledge, our data provide the first evidence of the replacement of a motor neuron unit within an animal model of a human motor neuron disease.

\section{Materials and Methods}

Animal models. Transgenic animals were purchased from The Jackson Laboratory (http://www.jax.org). All animal experiments were performed according to institutional guidelines in compliance with national and international laws (Corti et al., 2006). The nmd mouse (B6.BKS $\operatorname{Ighmbp} 2^{n m d-2 J} / \mathrm{J}$ ) harbors a homozygous mutation in the Ighmbp2 gene. Heterozygous mice were crossed to generate mice that were homozygous for the mutation. Homozygous nmd mutant mice and wild-type (wt) littermates were used for the experiments and analyses. As described previously (Cox et al., 1998), the mice were genotyped using a PCR-based assay using genomic DNA from tail biopsies. As cell donors, we used HB9-GFP transgenic mice that expressed enhanced green fluorescent protein (GFP) DNA under the control of the murine HB9 promoter in spinal motoneurons in embryonic day 9.5 (E9.5) to postnatal day 10 mice; this allowed identification of motoneurons (Wichterle et al., 2002).

Isolation and culture of neural stem/progenitor cells. NSCs were isolated from the ventricular zone (VZ) of spinal cords of E10.5 HB9-GFP and wt mice as described previously (Corti et al., 2006). Tissue was mechanically dissociated with a Pasteur pipette and incubated in a $0.05 \%$ trypsin/ EDTA solution for $15 \mathrm{~min}$ at $37^{\circ} \mathrm{C}$. For isolation of LeX + cells, a singlecell suspension from neurospheres was labeled with LeX (SSEA-1) microbeads (Miltenyi Biotec), and cells were purified by immunomagnetic selection according to the manufacturer's instructions. LeX + cells were grown in Neurobasal medium (Invitrogen), containing B-27, N2 (Invitrogen), epidermal growth factor $(20 \mathrm{ng} / \mathrm{ml}$; Sigma-Aldrich), fibroblast growth factor (FGF; $20 \mathrm{ng} / \mathrm{ml}$, Sigma-Aldrich), and penicillin (100 $\mathrm{U}) /$ streptomycin $(100 \mu \mathrm{g} / \mathrm{ml}$; Invitrogen). Cells were grown as an adherent monolayer, and cultures were passaged every 5-7 d. Cells used for antigen selection were passaged three to five times.

Fluorescence-activated cell-sorting analysis of LeX + cells. Cells selected by immunomagnetic selection were analyzed for LeX positivity by fluorescence-activated cell sorting (FACS). Cells were labeled with fluorescein isothiocyanate (FITC)-conjugated anti-LeX antibody (from mouse; also called anti-SSEA1; 1:200; BD Biosciences) for $30 \mathrm{~min}$ at $4^{\circ} \mathrm{C}$, centrifuged at $500 \times g$ for $5 \mathrm{~min}$, and washed twice with serum-free medium. In the case of HB9-GFP cells, we incubated cells with unlabeled anti-LeX (1:200; BD Biosciences) for $30 \mathrm{~min}$ at $4^{\circ} \mathrm{C}$; after rinsing, they were incubated for 20 min with R-phycoerythrin (R-PE) anti-mouse antibody (Dako). Isotype-matched mouse Ig (BD Biosciences) and cells labeled with only the secondary antibody served as controls. FACS was conducted using a FACS Vantage SE (BD Biosciences). Sorting of antibody-labeled cells was performed using FACS gates set with unlabeled cells.

Differentiation of LeX + cells. For in vitro differentiation, LeX + cells were cultured in Neurobasal plus N2 medium, $0.1 \mathrm{~mm}$ 2-mercaptoethanol, $20 \mathrm{ng} / \mathrm{ml}$ basic FGF, $1 \mu \mathrm{g} / \mathrm{ml}$ laminin, $5 \mu \mathrm{g} / \mathrm{ml}$ heparin, $10 \mathrm{ng} / \mathrm{ml}$ neural growth factor (Invitrogen), $10 \mathrm{ng} / \mathrm{ml}$ sonic hedgehog (Shh; R\&D Systems), $10 \mu \mathrm{M}$ forskolin (Sigma), and retinoic acid (RA; $1 \mu \mathrm{M}$; Sigma) (Corti et al., 2007). After 48-72 h, glial cell line-derived neurotrophic factor (GDNF), brain-derived neurotrophic factor, ciliary neurotrophic factor, insulin-like growth factor, and $10 \mathrm{ng} / \mathrm{ml}$ neurotrophin-3 (R\&D Systems) were added to the medium (Corti et al., 2007).

Immunocytochemistry of cultured cells. Cells were fixed in $4 \%$ paraformaldehyde (PFA) for $10 \mathrm{~min}$ at room temperature. After rinsing with PBS and preincubation with a mixture of 5\% normal serum and $0.25 \%$ Triton X-100 in PBS, the cultures were incubated with the primary antibodies (see below) overnight at $4^{\circ} \mathrm{C}$. The following proteins were evaluated using the diluted antibodies indicated in parentheses: nestin (mouse monoclonal antibody; 1:200; Millipore Bioscience Research Reagents), LeX (mouse antibody; 1:200; BD Biosciences), Sox2 (rabbit antibody;
1:200; Millipore Bioscience Research Reagents), Musashi-1 (rabbit antibody; 1:200; Millipore Bioscience Research Reagents), proliferating cell nuclear antigen (PCNA; mouse monoclonal antibody; 1:200; Millipore Bioscience Research Reagents), nuclear neural-specific antigen (NeuN; mouse monoclonal antibody; 1:100; Millipore Bioscience Research Reagents), anti-PDGFR $\alpha$ (platelet-derived growth factor receptor $\alpha$ ) antibody (clone APA5, 1:200; eBioscience), Olig2 (rabbit polyclonal antibody; 1:500; Millipore Bioscience Research Reagents), Irx3 (rabbit polyclonal antibody; 1:100; Santa Cruz Biotechnology), Nkx2.2 (rabbit polyclonal antibody;1:200; Millipore Bioscience Research Reagents), HOXC6 (goat polyclonal antibody; 1:100; Santa Cruz Biotechnology), HOXC8 (mouse antibody; 1:200; Covance), otx2 (rabbit polyclonal antibody; 1:200; Millipore Bioscience Research Reagents), En1 (rabbit polyclonal antibody; 1:200; Millipore Bioscience Research Reagents), HB9 (rabbit antibody; 1:200; Millipore Bioscience Research Reagents), Islet-1 (rabbit antibody; 1:200; Millipore Bioscience Research Reagents), TuJ-1 (mouse monoclonal antibody; 1:200; Millipore Bioscience Research Reagents), phosphorylated neurofilament (NF)-M and NF-H (mouse monoclonal antibody; 1:200; Millipore Bioscience Research Reagents), microtubule-associated protein 2 (MAP2; mouse monoclonal antibody; 1:100; Sigma-Aldrich), anti-choline acetyltransferase (ChAT; rabbit antibody; 1:100; Millipore Bioscience Research Reagents), and GFP (Alexa 488 rabbit polyclonal antibody; 1:400; Molecular Probes).

After repeated rinses with PBS, the cells that had been incubated with unconjugated primary antibodies were incubated for $1 \mathrm{~h}$ (room temperature in the dark) with secondary antibodies conjugated with FITC and R-PE or tetramethylrhodamine isothiocyanate (1:100 in PBS; Dako). Cells were rinsed in PBS, and a coverslip was applied.

No positive signals were detected using control cells incubated with secondary antibodies but not primary antibodies. For each slide, 10 monolayer fields (each with $>200$ cells) were randomly chosen for quantitative cell analysis. The percentage of a given phenotype (i.e., expression of a specific protein) in cells on a slide was calculated by averaging the proportion of cells expressing that protein in each of the 10 fields. At least four slides were assessed for each treatment group.

Motoneuron isolation and transplantation. Motoneurons were positively selected from HB9-GFP mice on the basis of p75-NTR antigen expression using magnetic cell separation (Miltenyi Biotec), as described previously (Arce et al., 1999; Locatelli et al., 2007). Motoneuron purity was evaluated by HB9-GFP expression using FACS analysis (FACS Vantage SE; BD Biosciences). Wild-type murine motoneurons were used as a control to set the cutoff value for background fluorescence.

Before cell transplantation, the positively selected motoneurons were resuspended in saline solution as described previously (Corti et al., 2007). The graft recipients were 14 -d-old $n m d$ mice. Cells were transplanted into the spinal cords of animals as described previously (Corti et al., 2007). A total of 10,000 cells $/ \mu \mathrm{l} \times$ two horns were injected slowly into cervical C4-C5 and lumbar L1/L2 regions of the recipients' spinal cords. As controls, nmd and wt mice received injections of vehicle using the same surgical procedure.

There were four groups of mice ( $n=24$ for each group; 12 males and 12 females). Group 1 ( $n m d$-trans; for transplant) received transplanted motoneurons; group 2 ( $n m d$-veh; for vehicle) received vehicle only (mock transplantation); group 3 ( $n m d$-trans + drugs; for transplant plus drugs) received both transplanted motoneurons plus drug therapy; and group 4 ( $n m d$-veh-drugs; for vehicle plus drugs; mock transplantation) plus drug therapy. The wt group $(n=24)$ were wt littermates of $n m d$ mice that received vehicle. We also transplanted a group of $n m d$ mice with murine fibroblasts as the control $(n=24)$.

Murine dermal fibroblasts (primary culture from neonatal skin) were cultured as controls, as described previously (Corti et al., 2008), and were prepared for transplantation identically to the motoneurons.

Littermates were distributed equally into the treated groups (groups 1 and 3 ) and untreated groups (groups 2 and 4). For group 3, motoneurons were suspended in a solution containing $1 \mathrm{~mm}$ dibutryl cAMP (dbcAMP) before transplantation. Two days before transplantation, and continuing after transplantation, mice were injected subcutaneously with $0.5 \mathrm{mg} /$ $\mathrm{kg} / \mathrm{d}$. Starting the day of transplantation, group 3 mice were also given 
injections of GDNF (10 ng/mg/d) in their limb muscles: biceps, triceps, quadriceps, tibialis anterior, and gastrocnemius.

The number of mice analyzed for each condition was: for histological analysis, $n=6$ for each group; for cytokine analysis, $n=5 n m d$-veh and $n m d$-trans + drugs; $n=6 n m d$-trans, $n m d$-veh + drugs, and wt; and for retrograde labeling with Fluorogold, $n=6$ for each group.

Mice in all groups were examined for disease phenotype (neuromuscular evaluation and survival). Donor cell histology was also evaluated.

Neuromuscular evaluation and survival. All groups of $n m d$ mice were monitored daily after transplantation or mock transplantation for clinical signs of disease. The investigators performing the functional assessment were blind to the treatment each mouse received. Body weight was recorded daily. Motor function was tested weekly using an accelerating rotarod device (4-40 rpm; Rota-Rod 7650; Ugo Basile). We recorded the length of time that each mouse remained on the rotarod. Mortality was scored as the age at death. The animals were killed when the mouse was unable to right itself within $30 \mathrm{~s}$ when placed on its back in a supine position (Li et al., 2000).

Tissue analysis. Mice were killed at the end stage of the diseases $(n=24$ for each condition) and perfused with 4\% PFA in PBS, pH 7.4. For each mouse, the spinal cord was isolated, immersed in PFA solution for $1 \mathrm{~h}$, immersed in a $20 \%$ sucrose solution in PBS, pH 7.4, overnight, and frozen in Tissue Tek O.C.T. compound using liquid nitrogen. The tissues were cryosectioned and mounted on gelatinized glass slides. Every tenth $20 \mu \mathrm{m}$ section was analyzed. Sections were blocked with $1 \%$ fetal calf serum in PBS and permeabilized with $0.25 \%$ Triton X-100. Sections were processed for multiple markers to determine the cellular phenotype of GFP-labeled cells. Sections were incubated overnight at $4^{\circ} \mathrm{C}$ with primary antibodies at the indicated dilutions: NeuN (mouse monoclonal antibody; 1:200; Millipore Bioscience Research Reagents); NF (mouse monoclonal antibody; 1:200; Millipore Bioscience Research Reagents); TuJ1 (mouse monoclonal antibody; 1:200; Millipore Bioscience Research Reagents); MAP2 (mouse monoclonal antibody; 1:200; SigmaAldrich); and anti-ChAT (rabbit polyclonal antibody; 1:100; Millipore Bioscience Research Reagents). Next, the sections that had been incubated with unconjugated primary antibodies were incubated for $1 \mathrm{~h}$ at room temperature with secondary antibodies at a 1:200 dilution: mouse or rabbit secondary antibodies conjugated with FITC, R-PE, CY3, or biotin (Jackson ImmunoResearch and Dako).

Primary antibodies identifying protein on blood immune cells were used to address the type and intensity of host-versus-graft cellular response: CD4 and CD8 (rat anti-mouse; 1:200; BD Biosciences); antiCD49b [natural killer (NK) cells; rat anti-mouse; 1:100; BD Biosciences], MAC-2 (activated microglia; rat anti-mouse; 1:100; Cedarlane).

An anti-GFP antibody (rabbit serum Alexa Fluor 488; 1:400 dilution; Invitrogen) was used to reveal GFP positivity. Coexpression of GFP and tissue-specific markers was evaluated by conventional fluorescence microscopy (Zeiss Axiophot) and by confocal laser-scanning microscopy (Leica TCS SP2 AOBS). Optical dissectors and random sampling were used to obtain an unbiased stereological estimation of GFP-positive cells. For donor cell quantification, a systematic random series of every tenth coronal section $(20 \mu \mathrm{m})$ was prepared from tissue throughout the entire spinal cord (a mean of 25 sections per animal).

Quantitative cell density was then estimated using the optical dissector method (Gundersen et al., 1988; Messina et al., 2000). Optical dissectors, $100 \times 70 \times 14 \mu \mathrm{m}$ in size, were sampled randomly, and the number of positive cells in each dissector was quantified. The density was calculated by dividing the total number of donor cells by the total volume of optical dissectors. The total volume of tissue per specimen $\left(V_{\text {cord }}\right)$ containing donor cells was calculated using the Cavalieri method. $V_{\text {cord }}$, multiplied by the number of donor cells/ $\mu \mathrm{m}^{3}\left(N_{\mathrm{v}}\right)$, gave the total number $(N)$ of donor cells per specimen: $N=N_{\mathrm{v}} \times V_{\text {cord }}$ (Messina et al., 2000). We analyzed all ventral roots within two levels of the injection sites by immunohistochemistry (as described above) for colocalized GFP and NF staining to identify donor cell-derived axons.

For neuromuscular junction staining, $30 \mu \mathrm{m}$ longitudinal sections were cut using a cryostat and mounted onto gelatin-coated slides. The sections were incubated for $3 \mathrm{~h}$ at room temperature with rhodamineconjugated $\alpha$-bungarotoxin (50 ng/ml; Invitrogen) in PBS. The slides were rinsed and mounted. A total of 70 neuromuscular junctions for each mouse was evaluated. The slides were observed through a confocal microscope (Leica) and analyzed with NIH ImageJ software.

Fluorogold was injected in three muscles (at 12 weeks): the gluteal muscles, quadriceps, and gastrocnemius complex as described previously (Haenggeli and Kato, 2002; Deshpande et al., 2006). The animals were killed $4 \mathrm{~d}$ after fluorogold injection ( $n=6$ per each group).

Histological analysis and motoneuron quantitation. For histological analysis, the lumbar spinal cord region ( $n=6$ for each group, at the end stage of the disease) was processed for paraffin embedding. Serial $12 \mu \mathrm{m}$ cross sections of the lumbar spinal cords were prepared, and one of every five sections ( $n=50$ for each mouse) was processed and Nissl stained as described previously (Grondard et al., 2005). The number and diameter of all motoneurons in each cross section were counted and analyzed. The sections were viewed at $200 \times$ magnification (Zeiss Axiophot) in the anterior horn (either left or right) for the presence of all neurons in that region. All cells were counted within the ventral horn below an arbitrary horizontal line drawn from the central canal. Only neuronal cells showing at least one nucleolus within the nucleus were counted, as described previously (Grondard et al., 2005).

Multiplex cytokine assay. The Procarta Protein Profiling Assays system (Panomics) was used to simultaneously detect 26 different mouse cytokines in spinal cord lysate samples. This assay uses xMAP technology (MultiAnalyte profiling; Luminex Technology) to detect and quantify multiple protein targets simultaneously. The cytokines analyzed were interleukin (IL)-9, IL-1- $\beta$, IL-2, IL-3, IL-4, IL-5, IL-6, IL-12P40, IL12P70, IL-17, IL-13, RANTES (regulated on activation, normal T expressed and secreted), interferon- $\gamma$, granulocyte-macrophage-colony stimulating factor, tumor necrosis factor- $\alpha$, macrophage inflammatory protein 1- $\alpha$ (MIP1- $\alpha$ ), Eotaxin, monocyte chemoattractant protein-1 (MCP1), IP10, MCP3, vascular endothelial growth factor, IL-23, IL-1- $\alpha$, transforming growth factor- $\beta$, and granulocyte colony-stimulating factor. This system was used to analyze lysates of spinal cords from each of the mice groups ( $n=5$ for nmd-veh and nmd-trans + drugs; $n=6$ nmd-trans, nmd-veh + drugs, and wt) as per the manufacturer's instructions. The samples were processed by Panomics according to the standard operating procedures of the company.

Statistical analysis. Kaplan-Meier survival analysis and the log-rank test were used for survival comparisons. The growth curve and rotarod tests were analyzed by ANOVA, followed by Tukey's post hoc analysis for multiple comparisons. The data for the number and size of motoneurons were evaluated by one-way ANOVA followed by Tukey's post hoc analysis. We used StatsDirect for Windows (version 2.6.4) for statistical analyses. In all analyses, the null hypothesis was rejected when $p$ was $<0.05$.

\section{Results}

\section{LeX + spinal cord neural stem/precursor cells can differentiate into motoneurons}

To determine whether LeX + embryonic NSCs can generate motoneurons, we isolated this fraction by immunomagnetic selection of VZ cells of the spinal cords from E10.5 mice and expanded the selected cells in vitro. FACS analysis showed that $70-98 \%$ of the isolated cells were LeX $+($ Fig. $1 a-c)$. In cell culture, these cells formed a monolayer and expressed the early stem/progenitor cell markers nestin (93.6 $\pm 3.7 \%)$ and LeX (Fig. $1 d-f)$. Furthermore, the majority of these cells coexpressed the CNS stem cell markers Sox2 $(96.8 \pm 3.9 \%)$ and Musashi-1 $(93.3 \pm 3.6 \%)$ and the proliferation marker PCNA (Fig. $1 g-l$ ); however, the cells were negative for markers of differentiated neurons or glia (NeuN and PDGFR) (supplemental Fig. 1, available at www.jneurosci.org as supplemental material). We also looked at whether the cultivated LeX+ neural stem/progenitor cells expressed transcription factors that are expressed in specific temporal and spatial patterns during spinal motoneuron differentiation. After $48-72 \mathrm{~h}$ of exposure to Shh, RA, and morphogens, the cells were positive for Olig2 (supplemental Fig. 2a,c, available at www.jneurosci.org as supplemental material) and negative for Irx3 and Nkx2.2 (data 
not shown). Importantly, these cells also expressed HOXC6 and HOXC8, which are markers of spinal cord motoneurons (supplemental Fig. 2d,e, available at www. jneurosci.org as supplemental material), but were negative for Otx2 and En1, neural markers that are characteristic of the rostral midbrain/hindbrain (data not shown). Thus, when appropriately stimulated in culture, LeX+ embryonic NSCs generated motoneurons.

To determine the percentage of motoneurons that were generated from the LeX + stem/progenitor cells after exposure to RA and Shh, we analyzed the expression of $\mathrm{HB} 9$, a homeodomain protein expressed selectively by somatic motoneurons (Wichterle et al., 2002). After $7 \mathrm{~d}$ of culture with RA and Shh, $33.3 \pm$ $3.2 \%$ of the cultured cells were HB9+ neurons that were also positive for Islet 1 (supplemental Fig. 2, available at www. jneurosci.org as supplemental material).

To more readily identify motoneurons, we isolated LeX + cells from HB9GFP transgenic mice, which express GFP in their motoneurons (Wichterle et al., 2002). HB9-GFP expression was detected at high levels in the axons and dendrites of motoneurons differentiated from LeX+ cells. Approximately $30-35 \%$ of the cells coexpressed high levels of endogenous HB9, GFP under control of the HB9 promoter, and Islet 1. The HB9-GFP motoneurons generated in vitro also expressed high levels of the neuronal proteins TuJ1, NF, MAP2, and ChAT (Fig. 2), suggesting positive cholinergic transmitter status. Together, these data suggest that the $\mathrm{LeX}+$ cells we isolated from the VZ of embryonic spinal cords are stem/progenitor cells that can become motoneurons.

Transplantation of selected HB9-GFP motoneurons, alone or in combination with pharmacological therapy to promote axonal elongation

Our next goal was to assess whether motoneurons derived from LeX + cells could survive and engraft appropriately within the $n m d$ spinal cord and whether transplantation would modify the SMARD1 disease phenotype in $n m d$ mice. As cell donors, we used HB9-GFP mice (Wichterle et al., 2002). Before transplantation, we purified HB9GFP motoneurons by positive immunomagnetic selection using the p75NTR surface antigen. motoneuron purity ranged from $70-98 \%$ as evaluated by FACS analysis of HB9-GFP expression (Fig. $2 h$ ). LeX + motoneurons $(10,000$ cells $/ \mu l \times$ two horns from cervical C4-C5 and lumbar L1/L2 spinal cords) were used for transplantation into the spinal cords of 14-day-old $n m d$ mice ( $n=24$ for each group of mice). There were four groups of mice. Group 1 (nmd-trans; for transplant) received transplanted motoneurons; group 2 ( $n m d$-veh; for vehicle) received vehicle only (mock transplantation); group 3 ( $n m d$-trans + drugs; for trans- plant plus drugs) received both transplanted motoneurons plus pharmacological agents to promote axonal extension (described below); and group 4 ( $n m$ d-veh-drugs; for vehicle plus drugs) received vehicle only plus the pharmacological agents. The wt group ( $n=24)$ were wt littermates of $n m d$ mice that received vehicle. Siblings were distributed equally in the groups, and each group had an equal number of males and females.

For mice receiving pharmacological agents, the treatment was as follows. Purified motoneurons were suspended in a solution containing $1 \mathrm{~mm}$ dbcAMP to promote neuron survival and axonal outgrowth (Deshpande et al., 2006). Two days before transplantation, and continuing daily after transplantation until the animals were killed, mice were given subcutaneous injections of rolipram, a compound that inhibits 

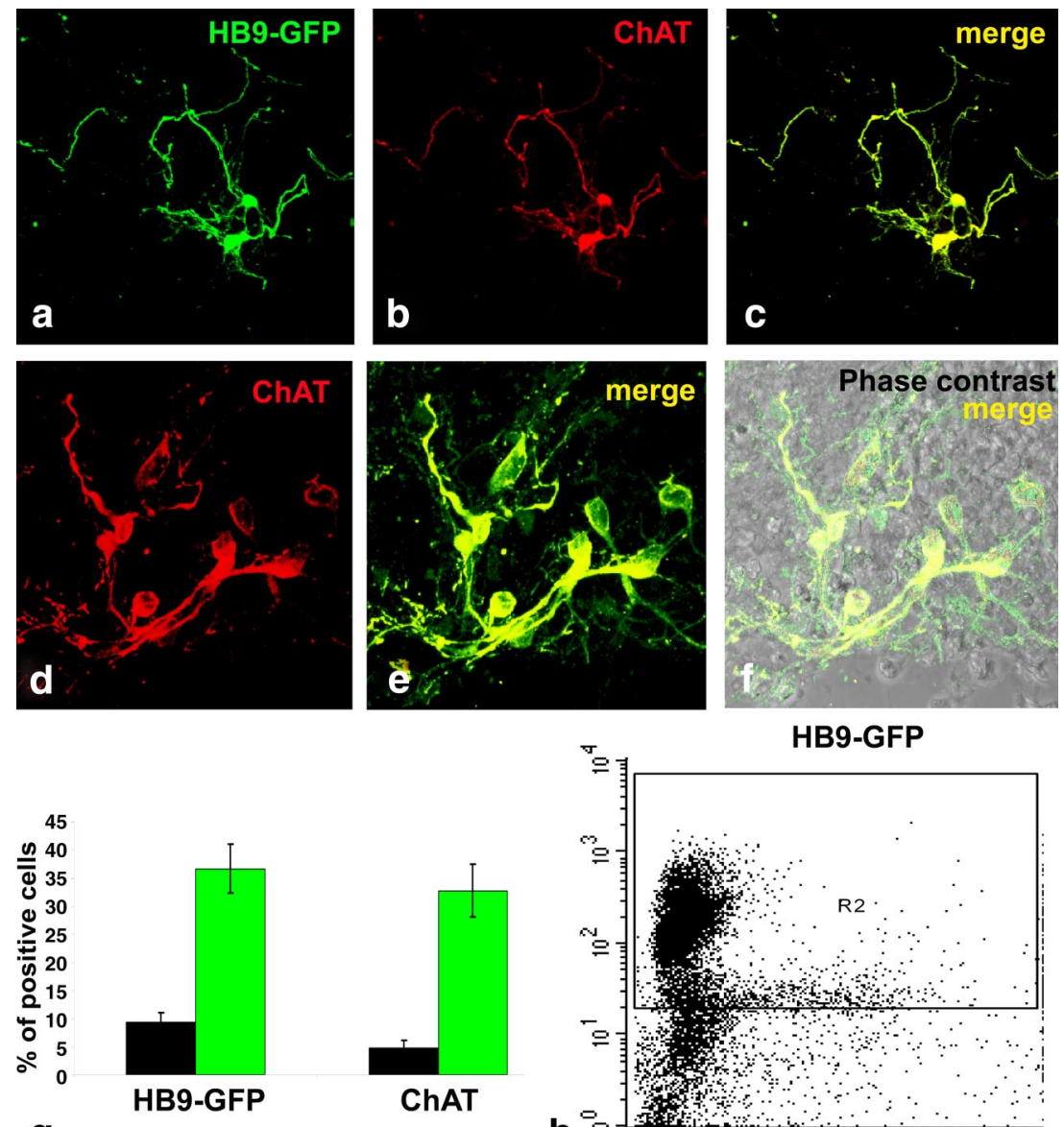

g
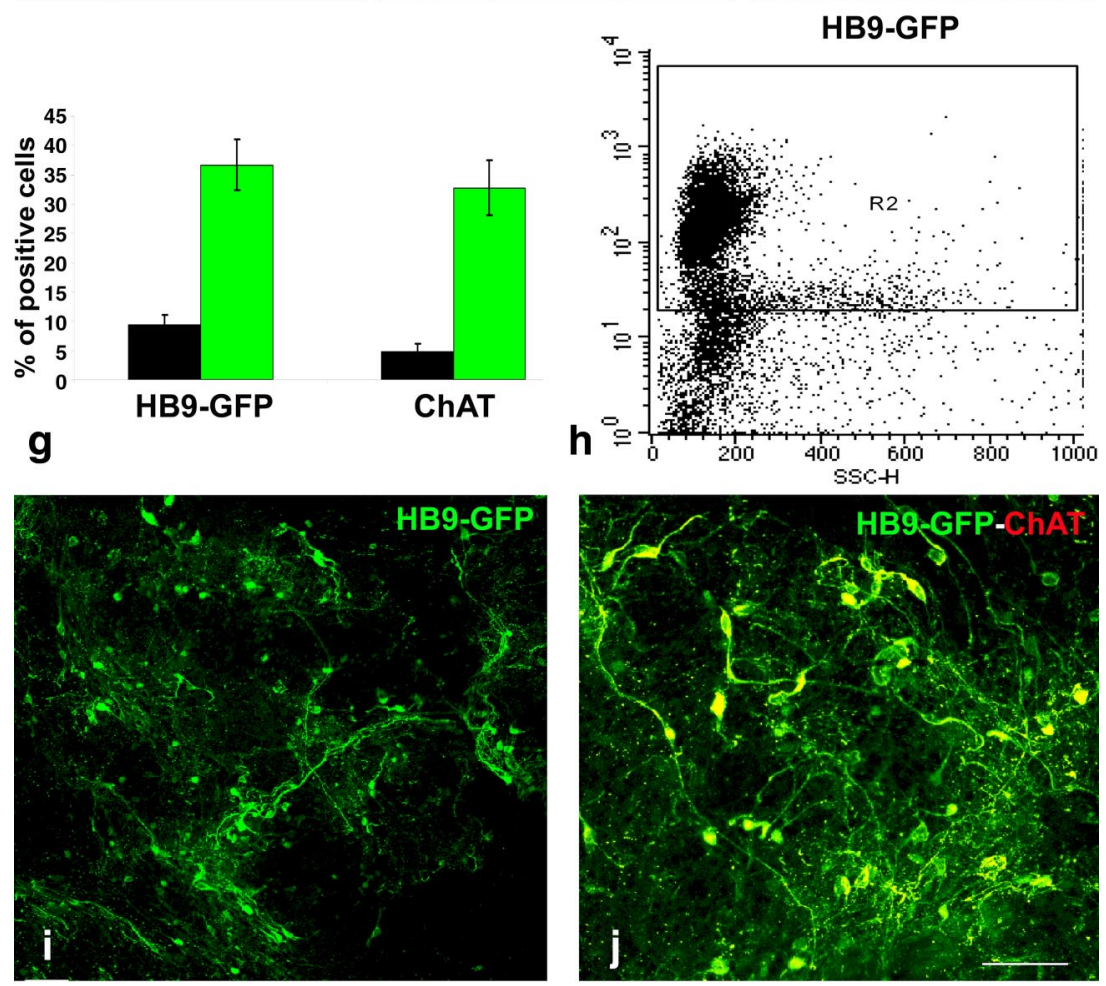

Figure 2. LeX+ cells can acquire a motoneuron phenotype in vitro. $\boldsymbol{a}, \boldsymbol{b}$, After in vitro differentiation, LeX + cells derived from HB9-GFP transgenic mice that express GFP protein (green) in motoneurons acquired a motoneuron phenotype as demonstrated by expression of GFP ( $\boldsymbol{a})$ and ChAT $(\boldsymbol{b}-\boldsymbol{d})$. $\boldsymbol{c}, \boldsymbol{e}$, Merged images. $\boldsymbol{f}$, Images merged with phase-contrast image. $\boldsymbol{g}$, Quantification of cells expressing HB9-GFP and ChAT after $48 \mathrm{~h}$ in culture (black bars) and after $7 \mathrm{~d}$ (green bars). Error bars represent SD. $\boldsymbol{h}$, FACS analysis of HB9-GFP expression as an indicator of motoneuron purity after selection for p75NTR surface antigen by immunomagnetic selection. $\boldsymbol{i}, \boldsymbol{j}$, Cultured HB9-GFP cells after immunomagnetic selection for p75NTR. The culture was enriched for cells positive for both HB9-GFP (i, $\boldsymbol{j})$ and ChAT (j; merged image of the green HB9-GFP signal with the red ChAT signal). Scale bar: $\boldsymbol{a}-\boldsymbol{c}, 80 \mu \mathrm{m} ; \boldsymbol{d}-\boldsymbol{f}$, $40 \mu \mathrm{m} ; \boldsymbol{i}, \mathbf{j}, 100 \mu \mathrm{m}$.

phosphodiesterase type 4 activity. We were expecting that rolipram treatment would overcome the inhibitory effects of myelin proteins on axonal extension (Deshpande et al., 2006). Starting the day of transplantation, mice were also given injections of GDNF, a growth factor that promotes axon growth (Deshpande et al., 2006). With the aim of attracting donor axons toward their targets, GDNF was injected in limb muscles: biceps, triceps, quadriceps, tibialis anterior, and gastroc- nemius. This combined drug treatment was referred to as dbcAMP + rolipram + GDNF treatment.

After treatment, mice in all groups were examined for disease phenotype (i.e., neuromuscular evaluation and survival). In addition, the spinal cord, spinal roots, and neuromuscular junctions were examined. There were no adverse effects in animals in any of the groups and no signs of excessive cell growth that could indicate tumor formation.

\section{Stem cell-derived motoneuron transplantation ameliorates the nmd phenotype}

All animal groups were examined for functional recovery by blind assessment of their overall appearance, weight, neuromuscular function (rotarod test), and survival after transplantation (Fig. 3). At 5 weeks, nmd-veh mutant mice presented with neuromuscular impairments on the rotarod test, but cage movements and feeding abilities were preserved; all failed the rotarod test and could maintain their position on the accelerating wheel for no longer than a few seconds $(p<0.00001$; $n m d$-veh vs wt) (Fig. 3d).

At 5 weeks of age, transplanted mice were still able to perform the rotarod test ( $p<0.00001 ; n m d$-trans vs $n m d$-veh and $n m d$-trans + drugs vs $n m d$-veh-drugs), although their performance was not as good as their wt siblings. At 8 weeks (Fig. 3d), the performance of transplanted $n m d$ mice on the rotarod test had improved; at the same time point, untreated $n m d$ mice [group 2 ( $n m d$-veh) and group 4 ( $n m d$-veh-drugs)] were still unable to perform the task $(p<0.00001 ; n m d$-trans vs $n m d$-veh and $n m d$-trans + drugs vs $n m d$-veh-drugs). Remarkably, group 3 mice ( $n m d$-trans + drugs) performed better than group 1 mice (nmd-trans) at 8 weeks $(p<0.00001)$.

Transplanted mice showed a marked improvement in body weight. When they were 8 weeks old, group 2 ( $n m d$-veh) had significantly reduced mean body weight compared with their control wt siblings (8 weeks: group 2, $12.4 \pm 1.8 \mathrm{~g}, n=24 \mathrm{vs} \mathrm{wt}$, $25.3 \pm 2.2 \mathrm{~g}, n=24 ; p<0.00001)$. However, group 1 ( $n m d$-trans) also weighed significantly more than group 2 ( $n$ mdveh; group 1: $16.8 \pm 1.1 \mathrm{~g}, n=24 ; p<$ 0.0001 compared with group 2) (Fig. 3c). Furthermore, group 3 ( $n m d$-trans + drugs) had increased mean body weight that was significantly different from group 4 ( $n m$ md-veh-drugs; group 3: $19.8 \pm$ $1.2 \mathrm{~g}, n=24$; group 4: $13.2 \pm 1.7 \mathrm{~g}, n=24 ; p<0.0001$ ) (Fig. $3 c$ ).

Group 1 ( $n m d$-trans) showed significantly improved survival compared with group 2 ( $n m d$-veh; group 1 vs group 2: log-rank test, $\chi^{2}=30.41, p<0.00001$ ). Indeed, group 3 (nmdtrans + drugs) survived longer than all other groups (group 3 vs 
group 1: log-rank test, $\chi^{2}=7.38, p=$ 0.0066; group 3 vs group 2: log-rank test, $\chi^{2}=45.77, p<0.00001$; group 3 vs group 4: $\log$-rank test; $\left.\chi^{2}=38.26, p<0.00001\right)$. We also transplanted a group of $n m d$ mice with murine fibroblasts as the control $(n=24)$.

Figure $3 b$ shows the Kaplan-Meier survival curves for the five groups of mice. Both male and female nmd transplanted mice had significantly increased mean life spans compared with gender- and siblingmatched nmd mice (supplemental Table 1 , available at www.jneurosci.org as supplemental material). Gender differences in the life spans of $n m d$ mice and other motor neuron disease animal models have been described previously (Maddatu et al., 2004; Corti et al., 2007). In our study, the maximum life span was $124 \mathrm{~d}$ in treated males and 142 in treated females (group 3); these life spans were longer than those of untreated $n m d$ mice (i.e., groups 2 and 4; group 2, $78 \mathrm{~d}$ for treated males and $91 \mathrm{~d}$ for untreated females; group 4, $80 \mathrm{~d}$ for treated males and $100 \mathrm{~d}$ for untreated females). This life span increase was specific to transplantation of motoneurons, since $n m d$ mice transplanted with murine primary fibroblasts did not show any significant improvement in survival compared with untreated mice (fibroblast transplanted males: $n=12$, $62 \pm 5.08$; females: $n=12,73.75 \pm 6.44$; fibroblast treated vs group 2: log-rank test, $\left.\chi^{2}=0.001691, p=0.96719\right)$.

\section{Transplanted LeX-selected motoneurons engraft in the nmd spinal cord}

We measured transplanted motoneuron survival and integration at the end stage of SMARD1 disease in $n m d$ mice. In all transplanted animals, we detected surviving transplant-derived motoneurons $(\mathrm{GFP}+)$ within the ventral horn gray matter of the recipients' spinal cords. Considering a line through the central canal perpendicular to the ventral spinal cord sulcus, the percentage of $\mathrm{GFP}(+)$ transplanted neurons in the ventral horn was $86.5 \pm 4.1 \%$ in group 1 (nmd-trans) and $87.4 \pm 3.8 \%$ in group 3 (nmd-trans +drugs). These transplant-derived motoneurons looked morphologically similar to the host motoneurons and expressed HB9-GFP, confirming their origin from the HB9-GFP donor. Interestingly, HB9-GFP neuron axons extended into the gray matter as well as into the surrounding white matter. However, in group 1 ( $n$ md-trans), only a few donor-derived axons extended into the spinal white matter. In contrast, in group 3 (nmd-trans + drug), we detected numerous donor-derived axons extending into the nearby white matter.

To quantify the survival and determine the fate of transplanted motoneuron cells within the host spinal cords, we performed unbiased stereological quantification using optical dissectors and random sampling. Transplant-derived cells were easily recognizable by their expression of the reporter HB9-GFP gene (which produces a green signal). We found a significant
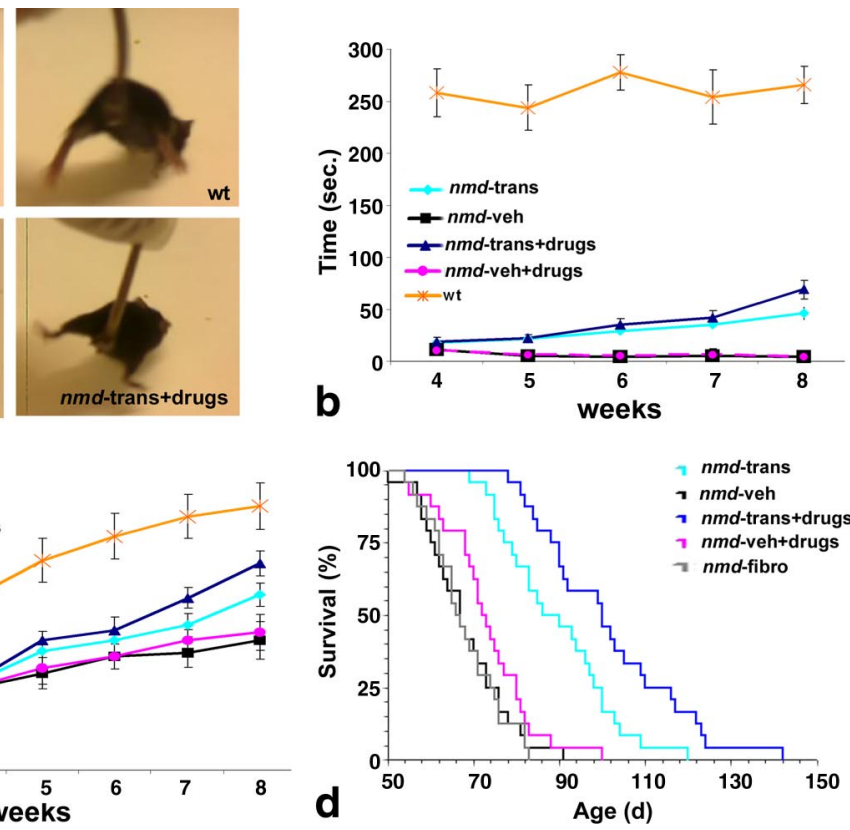

Figure 3. Motoneuron transplantation increases survival, reduces weight loss, and improves the neuromuscular function of nmd mice. nmd mice received transplanted motoneurons (nmd-trans, group 1) or transplanted motoneurons and bcAMP + rolipram + GDNF treatment (nmd-trans + drugs, group 3). Alternatively, nmd mice received vehicle only ( $n m d$-veh, 作 3 vs group 2: $\log$-rank test; $\chi^{2}=45.77, p<0.00001$; group 3 vs group 4 (nmdveh + drugs): log-rank test, $\chi^{2}=38.26, p<$ $0.00001)$. nmd mice transplanted with primary murine fibroblasts ( $n m d$-fibro) did not survive significantly longer than the untreated group (fibroblast treated vs group 2: $\log$-rank test, $\chi^{2}=0.001691, p=0.96719$ ).

difference in the total number of grafted HB9-GFP cells after transplantation in mice treated with motoneuron transplantation alone (3057 \pm 143 cells) compared with motoneuron transplantation combined with dbcAMP + rolipram + GDNF treatment (4763 \pm 312 cells) (group 1, nmd-trans vs group 3, nmdtrans + drugs; $p<0.00001)$

To characterize the neuronal phenotype of GFP + cells, we analyzed neuronal markers in spinal cord sections of recipient animals using immunohistochemistry and confocal microscopy. HB9-GFP motoneurons coexpressed several neuronal-specific antigens, including NF, MAP2, and NeuN (Fig. 4). Furthermore, these cells display a motor neuronal phenotype and coexpressed ChAT, indicative of cholinergic identity (Fig. 4). We found no signs of host immunoreaction to the donor cells or activated microglia when we looked at markers (CD4, CD8, CD49b, MAC2) of blood immune cells (lymphocytes and NK cells) (data not shown).

\section{Axonal extension in the periphery and neuromuscular junction formation between transplanted motor axons and host muscle}

We next examined whether dbcAMP + rolipram + GDNF treatment enhanced the outgrowth of transplant-derived axons, as suggested by the presence of GFP+ axons within the ventral 

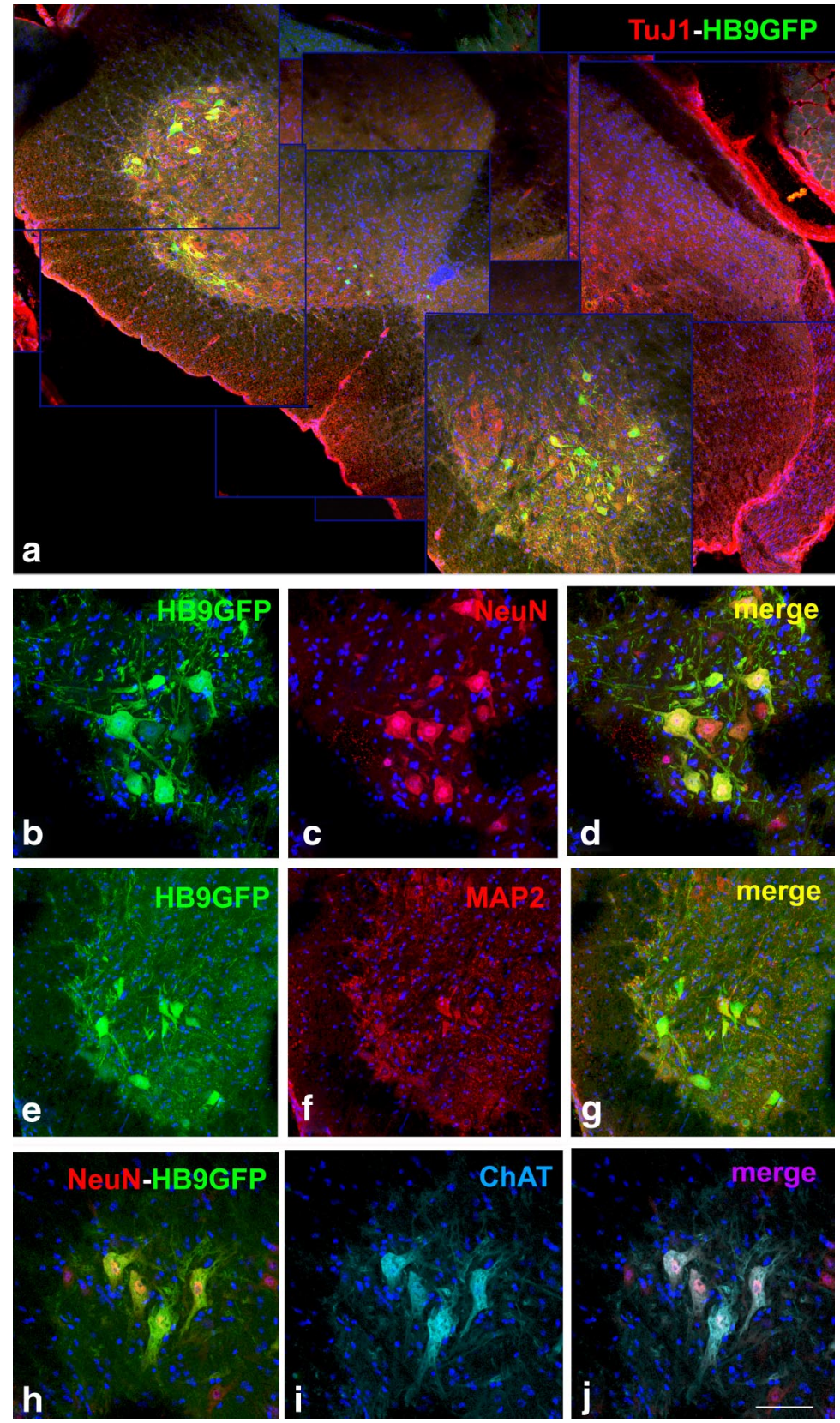

Figure 4. Motoneurons transplanted into $n m d$ mice engraft in the spinal cord anterior horns. Motoneurons derived from the LeX + fraction of HB9-GFP spinal cord were transplanted by intraparenchymal injection. GFP + motoneurons engrafted in the anterior horn of the spinal cord are shown in spinal cord coronal sections of treated nmd mice (group 1, nmd-trans). a, Merged image (composite image to present entire spinal cord) of red TuJ1 signal and green HB9-GFP signals. Immunohistochemistry of neuroectodermal markers confirmed that these cells displayed motoneuron characteristics. Confocal microscopy demonstrated that GFP motoneurons coexpressed neuron-specific proteins such as NeuN and MAP2. b, GFP (green). c, NeuN (red). d, Merged image. $\boldsymbol{e}$, GFP (green). $\boldsymbol{f}$, MAP2 (red). $\boldsymbol{g}$, Merged image. $\boldsymbol{h}-\boldsymbol{j}$, GFP motoneurons had a cholinergic phenotype as shown by ChAT expression: $\boldsymbol{h}$, merge of GFP (green) and NeuN (red); $\boldsymbol{i}$, ChAT (light blue); $\boldsymbol{j}$, merged image of $\boldsymbol{h}$ and $\boldsymbol{i}$. Nuclei were stained with DAPI (blue). Scale bar: $\boldsymbol{a}, 250 \mu \mathrm{m} ; \boldsymbol{b}-\boldsymbol{d}, 75 \mu \mathrm{m} ; \boldsymbol{e}-\boldsymbol{g}, 100 \mu \mathrm{m} ; \boldsymbol{h}-\boldsymbol{j}, 50 \mu \mathrm{m}$.

roots. We analyzed all the ventral roots within the two injection site levels by counting the number of GFP + axons that colocalized with NF as detected using immunohistochemistry. Group 3 ( $n$ md-trans + drugs) had more transplant-derived axons that reached the peripheral nervous system than group 1 ( $n m d$ trans; $211 \pm 25$ vs $63 \pm 5)$. No GFP + axons were observed in the dorsal roots.

We also examined muscle tissue from transplanted animals (groups 1 and 3) by confocal microscopy to determine whether connections established between stem cell-derived axons and skeletal muscle targets could be responsible for the observed functional recovery (Fig. 5).

We detected GFP-labeled axons in bicep, tricep, quadricep, tibialis anterior, and gastrocnemius skeletal muscle tissue only in mice with combined cell-drug treatment. HB9-GFP donor-derived axons exhibited branched morphology with growth cones that were positive for NF antigens. Using rhodamine-conjugated $\alpha$-bungarotoxin, we also observed acetylcholine receptor clustering that was complementary to the HB9-GFP axon positions (Fig. 5; supplemental movie 1, available at www.jneurosci.org as supplemental material). Notably, the morphology of the newly generated neuromuscular junctions was similar to the endogenous neuromuscular junctions.

To further confirm that donor-derived axons reached their skeletal muscle targets, we retrogradely labeled spinal motoneurons by injecting Fluorogold into the quadriceps and gastrocnemius muscles of transplanted mice. We then analyzed the host spinal cord for the presence of HB9-GFP donor-derived motoneurons retrogradely labeled with Fluorogold (Fig. 5) by confocal analysis and unbiased stereological counting. We detected $113 \pm$ 31 dual-labeled motoneurons per animal in group $3(n=6)$. Only a few $(<10$ motoneurons) were double positive for GFP and Fluorogold in group 1 mice $(n=6)$. In group 3 mice, $\sim 4700$ new $\mathrm{HB} 9+$ neurons were generated in the spinal cord, 200 new motor axons in the ventral roots, and 110 retrogradely labeled new motoneurons in skeletal muscle.

\section{Motoneuron transplantation is neuroprotective because of anti-inflammatory action}

In addition to contributing to the formation of neuromuscular junctions, it was possible that cell transplantation had other positive effects on endogenous motoneurons that contributed to the functional recovery of nmd mice with transplanted motoneurons. To investigate this, we analyzed spinal cord tissue from the four groups of $n m d$ mice and wt mice $(n=6$ for each group). Specifically, we examined the number and size of motoneurons in the ventral horn of the lumbar spinal cords. The untreated $n m d$ mice showed substantial motoneuron loss, with a $59.43 \%$ reduction compared with wt mice $(p<0.00001)$. The mean number of ventral horn neurons per horn per section in wt mice was 10.6, compared with 4.3 in group 2 ( $n m d$-veh) and 7.3 in group 1 ( $n m d$-trans) (supplemental Fig. $3 e$, available at www.jneurosci.org as supplemental material). Counting spinal cord neurons showed that cell transplantation conferred significant 

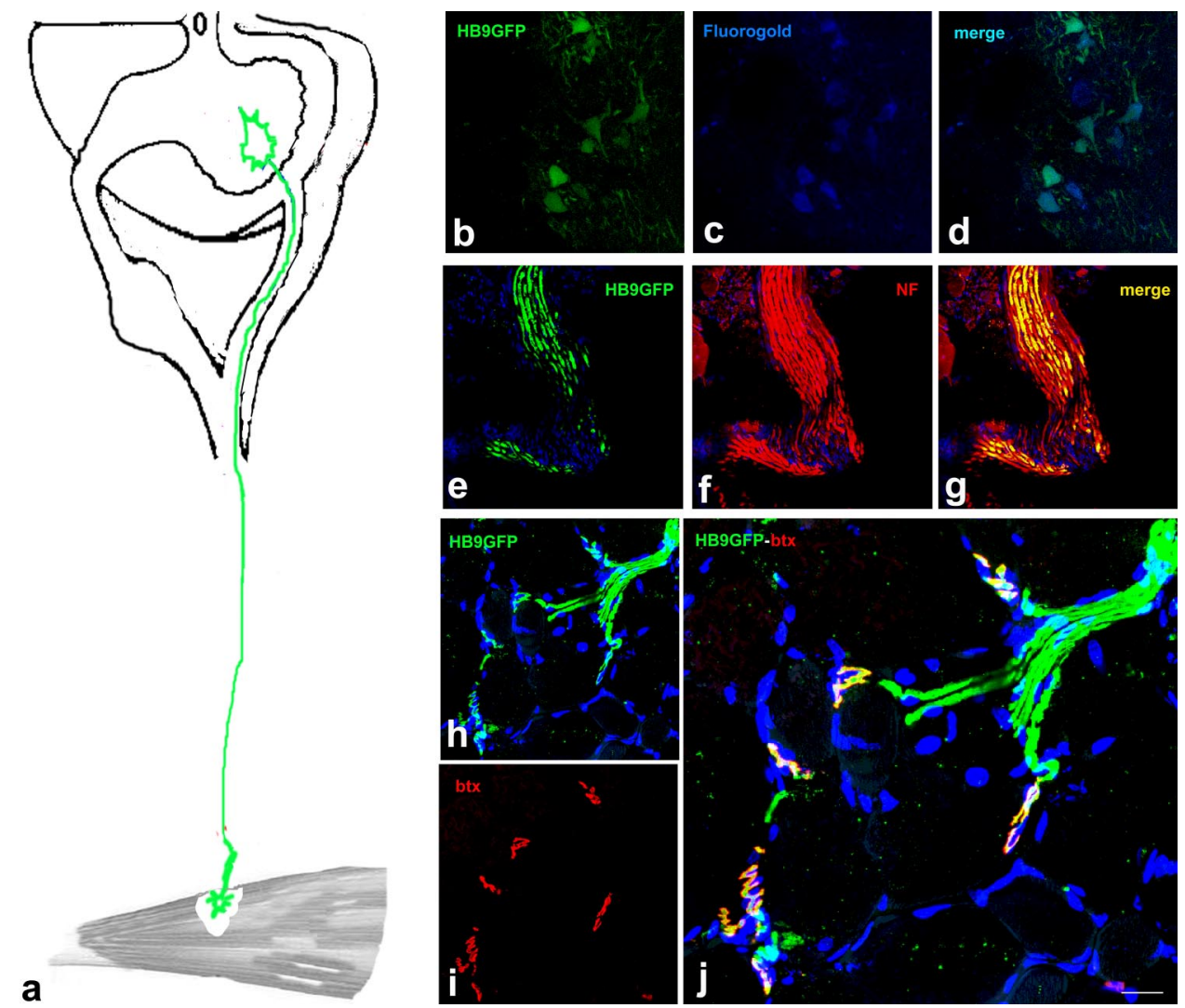

Figure 5. Transplanted motoneuron axons reach their skeletal muscle targets in $n m d$ mice. $\boldsymbol{a}$, Schematic diagram of a motoneuron with its axon forming a connection with muscle. $\boldsymbol{b}$ - $\boldsymbol{d}$, Transplanted HB9-GFP motoneurons (green) in the $n m d$ spinal cord (from group 3, nmd-trans + drugs mouse) were retrogradely labeled with Fluorogold (blue), showing their connection with the muscle. $\boldsymbol{d}$, Merged image of $\boldsymbol{b}$ and $\boldsymbol{c} . \boldsymbol{e}-\boldsymbol{g}$, Donor-derived GFP axons were detected in the anterior roots. $\boldsymbol{e}$, GFP (green signal). $\boldsymbol{f}$, NF (red signal). $\boldsymbol{g}$, Merged image of $\boldsymbol{e}$ and $\boldsymbol{f}$. $\boldsymbol{h}-\boldsymbol{j}$, HB9-GFP axons $(\boldsymbol{h}$, green) reached the muscle and formed new neuromuscular junctions, identified by rhodamine-conjugated bungarotoxin (btx; $\boldsymbol{i}$ ) with the host skeletal muscle. $\boldsymbol{j}$, Merged image. Scale bar: $\boldsymbol{b}-\boldsymbol{d}, \boldsymbol{h}, \boldsymbol{i}, 75 \mu \mathrm{m} ; \boldsymbol{e}-\boldsymbol{g}, 50 \mu \mathrm{m} ; \boldsymbol{j}, 30 \mu \mathrm{m}$

protection, with only a $31.13 \%$ reduction $(p<0.00001)$. The stereological count (based on ChAT and GFP immunoreactivity), the position within the anterior horns, and the cell diameter $(>25 \mu \mathrm{m})$ showed $1.94 \pm 0.29$ donor neurons per horn per section $(\mathrm{ChAT}+\mathrm{HB} 9+)$. Based on these data, donor neurons represented $26.6 \%$ of total motoneurons, and the endogenous motoneurons were also increased by $24.6 \%$ compared with untreated mice.

Motoneurons had a mean diameter of $36.6 \mu \mathrm{m}$ in wt littermates, $30.1 \mu \mathrm{m}$ in group 2 ( $n m d$-veh), and $33.2 \mu \mathrm{m}$ in group 1 (nmd-trans) (supplemental Fig. $3 f$, available at www.jneurosci. org as supplemental material) $(p<0.00001)$. Group 3 mice (nmd-trans +drugs) showed a greater increase in motoneuron number (a mean of 8.8 cells; $p<0.00001$ vs each other group) and size (a mean diameter of $34.8 \mu \mathrm{m} ; p<0.00001$ vs each other group). In group 3, there were $3.09 \pm 0.31$ donor neurons per horn per section $(\mathrm{ChAT}+\mathrm{HB} 9+)$. Based on these data, donor neurons represented $\sim 35.1 \%$ of all motoneurons, whereas the number of endogenous motoneurons increased by $32.8 \%$ compared with untreated mice.

We also wanted to investigate changes in the spinal cord microenvironment after cell transplantation that could contribute to the observed neuroprotective effects. A Luminex MultiAnalyte profile (xMAP) assay was used to simultaneously profile and quantify cytokines of spinal cord tissues of the four groups of $n m d$ and wt mice (Fig. 6).

Spinal cords of group 2 ( $n m d$-veh) expressed significantly higher levels of several chemokines compared with treated mice and wt mice. Compared with transplanted (groups 1 and 3) and wt mice, there was an approximate threefold (mean) increase in MCP1 and MCP3 in the spinal cords of $n m d$-veh mice (MCP1: group 2 vs group $1, p=0.000039$; group 2 vs group $3, p=$ 0.000028 ; group 2 vs wt, $p=0.00002 ; \mathrm{MCP} 3$ : group 2 vs group 1 , $p=0.000028$; group 2 vs group $3, p=0.0002$; group 2 vs wt, $p<$ $0.00001)$ and an approximate twofold increase of RANTES (group 2 vs group $1, p=0.03$; group 2 vs group $3, p=0.011$; group 2 vs wt, $p=0.016$ ). MIP1 was increased ninefold in $n m d$ veh mice compared with group 1 ( $n m d$-trans) mice $(p=0.001)$; it was undetectable in the group 3 mice ( $n m d$-trans + drugs) and in the wt group (group 2 vs group 3, $p=0.0003$; group 2 vs wt, $p=0.0003)$. Moreover, spinal cords from $n m d$-veh mice expressed significantly higher levels of IL- $1 \beta$ than transplanted $n m d$ mice (vs group $1, p=0.02$; vs group $3, p=0.00066$ ) and wt mice (IL-1 $\beta, p=0.00041)$. IL- $1 \alpha$ showed a significant increased level in $n m d$-veh mice with respect to wt mice $(p=0.0052)$ and a higher level in $n m d$-veh mice with respect to transplanted mice, even if not significant (vs group $1, p=0.076$; vs group $3, p=0.07$ ). All other tested cytokines did not differ significantly between the different groups. These data suggest that the improvements that we measured and observed in treated SMARD1 mice can be attributed, in part, to signaling changes in the spinal cord microenvironment after transplantation.

\section{Discussion}

SMARD1 is a motor neuron disease in infants that is characterized by muscle weakness and respiratory distress with poor prog- 

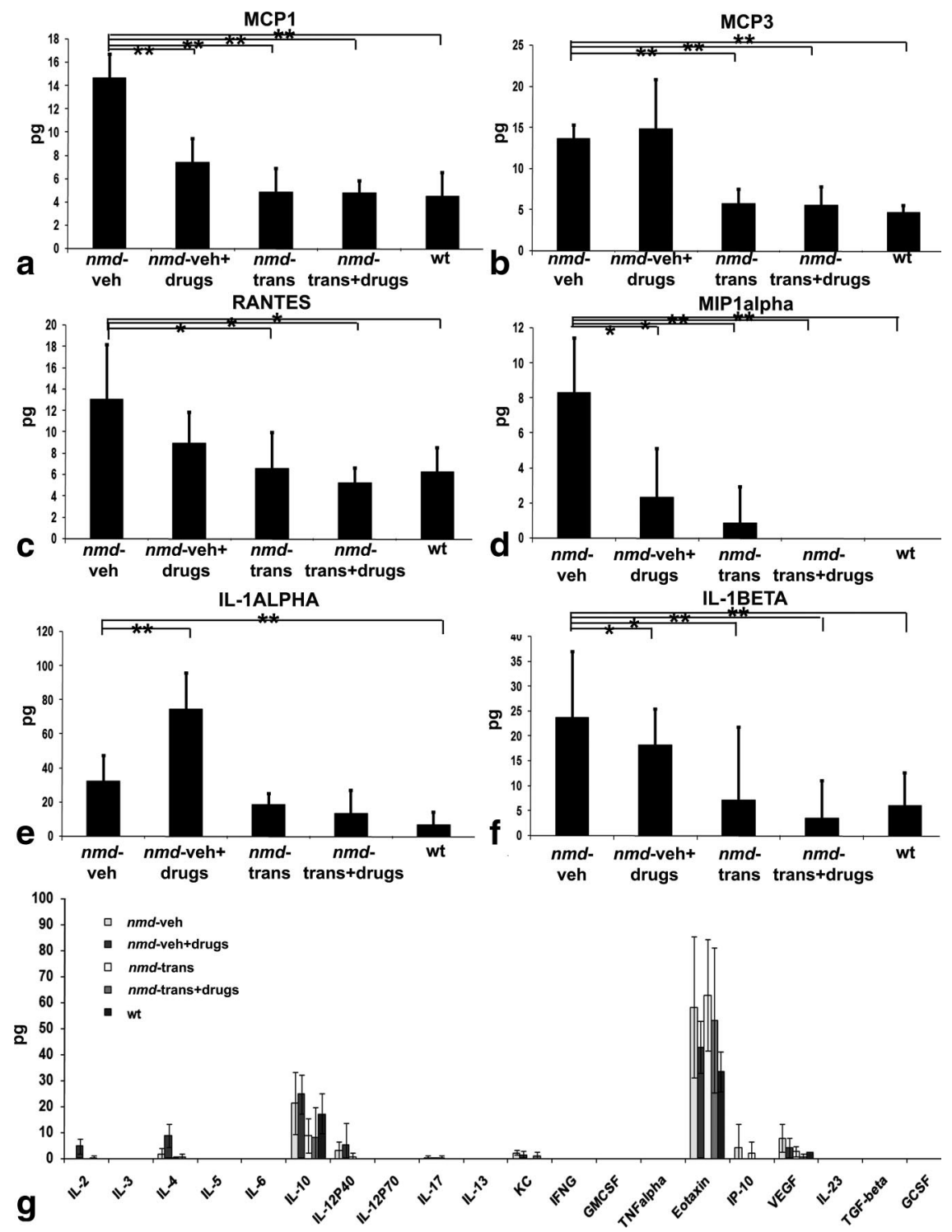

Figure 6. Profiles of cytokines expressed in the spinal cords of treated and untreated $n m d$ mice. The XMAP assay was used to simultaneously detect and quantify 26 cytokines in the spinal cord tissues from $n m d$ mice in each of the four groups [group 1 (nmd-trans; for transplant) received transplanted motoneurons; group 2 ( $n m d$-veh; for vehicle) received vehicle only (mock transplantation); group 3 (nmd-trans + drugs; for transplant plus drugs) received both transplanted motoneurons plus pharmacological agents to promote axonal extension (described below); and group 4 (nmd-veh-drugs; for vehicle plus drugs) received vehicle only plus the pharmacological agents] and wt mice. $\boldsymbol{a}, \boldsymbol{b}$, The chemokines MCP1 and MCP3 were expressed at significantly higher levels in the spinal cords of group 2 ( $n m d-v e h$ ) than in transplanted (groups 1 and 3 ) and wt mice. $c$, RANTES was expressed at a significantly higher levels ( $\sim$-fold higher) in $n m d$-veh compared with the transplanted (groups 1 and 3 ) and wt groups. $\boldsymbol{d}$, MIP1 was expressed at a significantly higher level ( $\sim 9$-fold higher) in $n m d$-veh compared with group 1 (nmd-trans), whereas it was undetectable in group 3 ( $n m d$-trans + drugs) mice and in the wt group. $\boldsymbol{e}$, Spinal cords from $n m d$-veh mice expressed significantly higher levels of IL-1 $\beta$ than transplanted $n m d$ mice (groups 1 and 3). $f$, IL-1 $\alpha$ showed a significant increased level in $n m d$-veh mice with respect to wt mice and a higher level in $n m d$-veh mice with respect to transplanted mice, even if not significant. $\boldsymbol{g}$, Other proinflammatory cytokines were either not expressed in measurable amounts or the differences between the groups of mice were nonsignificant. $\left.{ }^{* *} p<0.01 ;{ }^{*} p<0.05\right)$. Error bars represent SD.

nosis. SMARD1 is caused by a genetic defect; specifically, it results from mutations in the IGHMBP2 gene. There is no effective treatment for SMARD1 or for many other motor neuron diseases; however, recent preliminary experimental evidence has suggested that stem cell transplantation may be useful in developing therapies to treat these diseases (Harper et al., 2004; Maddatu et al., 2004; Corti et al., 2005, 2007, 2008; Deshpande et al., 2006; Yan et al., 2007). The current experiments showed that stem cell-derived motoneurons engraft efficiently in the $n m d$ mouse spinal cord: the axons elongate toward their muscle target, and the SMARD1 phenotype is diminished. To our knowledge, this study is thus the first to demonstrate that transplantation of terminally differentiated motoneurons ameliorates the SMARD1 phenotype.

We established an efficient preclinical protocol to promote functional substitution of motor units in symptomatic SMARD1 mice using stem cell-derived motoneurons. The first critical step of this in vitro protocol was the directed differentiation of a subset of pluripotent embryonic spinal cord-derived stem cells into committed motoneurons using Shh, RA, and other morphogens. The subset of cells was selected by LeX expression using immunomagnetic separation. LeX, a developmentally regulated tetrasaccharide carbohydrate, is abundantly expressed in embryonic and adult NSCs and can be used to isolate primitive stem cell fractions (Corti et al., 2007). We demonstrated previously that LeX + cells derived from embryonic spinal cords represent a stem cell/precursor population that can be expanded in vitro while maintaining the potential to generate motoneurons.

The second step of the protocol was the purification of motoneurons by immunomagnetic selection for p75NTR. This results in cells with a high degree of purity in terms of a motoneuronal phenotype, as assessed by HB9-GFP expression. These purified stem cell-derived motoneurons were then transplanted into nmd mice that were monitored for phenotypic and histopathological changes.

Donor-derived motoneurons appropriately engrafted in the anterior spinal cords of transplanted mice and displayed specific motoneuron marker proteins as well as a cholinergic phenotype. Interestingly, transplanted $n m d$ mice [group 1 (nmd-trans)] had a significantly longer life span: survival was prolonged by $\sim 30 \%$ compared with vehicle-treated mice $(p<$ $0.00001)$. A third group of $n m d$ mice received both transplanted cells and treatment with dbcAMP + rolipram + GDNF to promote axon elongation. In this group, mean survival was prolonged by $\sim 40 \%$ compared with the untreated or drugtreatment-only groups [group 2 ( $n m d$-veh) and group 4 ( $n m d-$ veh-drugs); $p<0.00001$ ]. Moreover, the beneficial effects of transplanted motoneurons seemed to be specific since they were not observed after transplantation of fibroblasts.

Motoneuron transplantation significantly improved functional parameters compared with untreated $n m d$ mice. This improvement correlated with histopathological changes in the spinal cords of transplanted mice, which showed motoneurons that were increased both in size and number. 
It was reported previously that murine ES-derived motoneurons transplanted into rat spinal cords are capable of extending axons toward host muscles as well as occasionally forming functional neuromuscular junctions (Harper et al., 2004). The myelin inhibitory signals were themselves inhibited by intraspinal infusion of dbcAMP and systemic administration of the phosphodiesterase 4 inhibitor rolipram (Deshpande et al., 2006). In addition, cells that were genetically engineered to express GDNF have been transplanted in the sciatic nerve to attract transplant-derived axons distally, resulting in the formation of host/transplant neuromuscular junctions (Deshpande et al., 2006). In the current study, we combined preincubation of cells with dbcAMP with in vivo administration of rolipram after transplantation.

GDNF was injected directly into muscle groups to attract the growing axons. It is notable that drug stimulation alone did not modify the nmd phenotype. However, newly formed neuromuscular junctions were significantly more abundant in nmdtrans + drugs mice. Furthermore, mice that received both cell transplantation and dbcAMP + rolipram + GDNF treatment had an improved phenotype compared with mice that received only transplanted cells. This indicates that the newly generated neuromuscular junctions contributed to the observed improvement in nmd symptoms.

In addition to the formation of new neuromuscular junctions, we wanted to determine whether other mechanisms contributed to the observed amelioration of the $n m d$ phenotype. Toward this end, we evaluated the profile of spinal cord cytokines in mice in different treatment groups as well as in wt mice. Vehicle-treated nmd spinal cords secreted both chemokines (MCP1, MCP3, RANTES, and MIP1 $\alpha$ ) and proinflammatory cytokines (IL- $1 \alpha$ and IL-1 $\beta$ ), whereas treated (groups 1 and 3 ) and wt mice did not.

Chemokines are implicated in many CNS diseases. Their primary role is to induce inflammation through the recruitment of leukocytes by their chemotactic activity and to increase the levels of proinflammatory molecules and chemokines; this has been described in detail in tissues from ALS patients (Nguyen et al., 2001). For instance, expression of the chemokine MCP1, which attracts monocytes and myeloid dendritic cells, is increased in humans with ALS and in a mouse model of ALS (Henkel et al., 2004, 2006; Baron et al., 2005). In ALS, it is unclear whether these signals simply modulate the innate immune response or if they contribute to motoneuron degeneration as well.

Our data suggest that intraspinal transplantation of motoneurons in nmd mice results in cell replacement and that transplanted neurons can establish axonal connections; furthermore, transplantation enhances anti-inflammatory modulation to promote secondary neuroprotection. Both mechanisms are likely to have contributed to the observed improvement in the phenotype, although the definition of the relative role of each mechanism or the existence of a synergistic effect should be investigated further. We also conclude that functional restoration of motor units with stem cell-derived motoneurons is feasible and therapeutic in the SMARD1 mouse model. These experiments may have relevance for potential therapeutic intervention in humans with SMARD1 and other motor neuron disorders.

\section{References}

Arce V, Garces A, de Bovis B, Filippi P, Henderson C, Pettmann B, deLapeyrière O (1999) Cardiotrophin-1 requires LIFRbeta to promote survival of mouse motoneurons purified by a novel technique. J Neurosci Res 55:119-126.

Baron P, Bussini S, Cardin V, Corbo M, Conti G, Galimberti D, Scarpini E, Bresolin N, Wharton SB, Shaw PJ, Silani V (2005) Production of mono- cyte chemoattractant protein-1 in amyotrophic lateral sclerosis. Muscle Nerve 32:541-544.

Corti S, Locatelli F, Papadimitriou D, Donadoni C, Del Bo R, Fortunato F, Strazzer S, Salani S, Bresolin N, Comi GP (2005) Multipotentiality, homing properties, and pyramidal neurogenesis of CNS-derived LeX(ssea-1)+/CXCR4+ stem cells. FASEB J 19:1860-1862.

Corti S, Locatelli F, Papadimitriou D, Donadoni C, Del Bo R, Crimi M, Bordoni A, Fortunato F, Strazzer S, Menozzi G, Salani S, Bresolin N, Comi GP (2006) Transplanted ALDHhiSSClo neural stem cells generate motor neurons and delay disease progression of $n m d$ mice, an animal model of SMARD1. Hum Mol Genet 15:167-187.

Corti S, Locatelli F, Papadimitriou D, Del Bo R, Nizzardo M, Nardini M, Donadoni C, Salani S, Fortunato F, Strazzer S, Bresolin N, Comi GP (2007) Neural stem cells LewisX+ CXCR4 + modify disease progression in an amyotrophic lateral sclerosis model. Brain 130:1289-1305.

Corti S, Nizzardo M, Nardini M, Donadoni C, Salani S, Ronchi D, Saladino F, Bordoni A, Fortunato F, Del Bo R, Papadimitriou D, Locatelli F, Menozzi G, Strazzer S, Bresolin N, Comi GP (2008) Neural stem cell transplantation can ameliorate the phenotype of a mouse model of spinal muscular atrophy. J Clin Invest 118:3316-3330.

Cox GA, Mahaffey CL, Frankel WN (1998) Identification of the mouse neuromuscular degeneration gene and mapping of a second site suppressor allele. Neuron 21:1327-1337.

Deshpande DM, Kim YS, Martinez T, Carmen J, Dike S, Shats I, Rubin LL, Drummond J, Krishnan C, Hoke A, Maragakis N, Shefner J, Rothstein JD, Kerr DA (2006) Recovery from paralysis in adult rats using embryonic stem cells. Ann Neurol 60:32-44.

Fukita Y, Mizuta TR, Shirozu M, Ozawa K, Shimizu A, Honjo T (1993) The human $S$ mu bp-2, a DNA-binding protein specific to the single-stranded guanine-rich sequence related to the immunoglobulin mu chain switch region. J Biol Chem 268:17463-17470.

Grohmann K, Schuelke M, Diers A, Hoffmann K, Lucke B, Adams C, Bertini E, Leonhardt-Horti H, Muntoni F, Ouvrier R, Pfeufer A, Rossi R, Van Maldergem L, Wilmshurst JM, Wienker TF, Sendtner M, RudnikSchöneborn S, Zerres K, Hübner C (2001) Mutations in the gene encoding immunoglobulin mu-binding protein 2 cause spinal muscular atrophy with respiratory distress type 1 . Nat Genet 29:75-77.

Grohmann K, Varon R, Stolz P, Schuelke M, Janetzki C, Bertini E, Bushby K, Muntoni F, Ouvrier R, Van Maldergem L, Goemans NM, Lochmüller H, Eichholz S, Adams C, Bosch F, Grattan-Smith P, Navarro C, Neitzel H, Polster T, Topaloğlu H, et al. (2003) Infantile spinal muscular atrophy with respiratory distress type 1 (SMARD1). Ann Neurol 54:719-724.

Grohmann K, Rossoll W, Kobsar I, Holtmann B, Jablonka S, Wessig C, Stoltenburg-Didinger G, Fischer U, Hübner C, Martini R, Sendtner M (2004) Characterization of Ighmbp2 in motor neurons and implications for the pathomechanism in a mouse model of human spinal muscular atrophy with respiratory distress type 1 (SMARD1). Hum Mol Genet 13:2031-2042.

Grondard C, Biondi O, Armand AS, Lécolle S, Della Gaspera B, Pariset C, Li H, Gallien CL, Vidal PP, Chanoine C, Charbonnier F (2005) Regular exercise prolongs survival in a type 2 spinal muscular atrophy model mouse. J Neurosci 25:7615-7622.

Gundersen HJ, Bagger P, Bendtsen TF, Evans SM, Korbo L, Marcussen N, Moller A, Nielsen K, Nyengaard JR, Pakkenberg B, et al. (1988) The new stereological tools: dissector, fractionator, nucleator and point sampled intercepts and their use in pathological research and diagnosis. APMIS 96:857-881.

Haenggeli C, Kato AC (2002) Rapid and reproducible methods using fluorogold for labelling a subpopulation of cervical motor neurons: application in the wobbler mouse. J Neurosci Methods 116:119-124.

Harper JM, Krishnan C, Darman JS, Deshpande DM, Peck S, Shats I, Backovic S, Rothstein JD, Kerr DA (2004) Axonal growth of embryonic stem cellderived motor neurons in vitro and in motor neuron-injured adult rats. Proc Natl Acad Sci U S A 101:7123-7128.

Hedlund E, Hefferan MP, Marsala M, Isacson O (2007) Cell therapy and stem cells in animal models of motor neuron disorders. Eur J Neurosci 26:1721-1737.

Henkel JS, Engelhardt JI, Siklós L, Simpson EP, Kim SH, Pan T, Goodman JC, Siddique T, Beers DR, Appel SH (2004) Presence of dendritic cells, MCP-1, and activated microglia/macrophages in amyotrophic lateral sclerosis spinal cord tissue. Ann Neurol 55:221-235.

Henkel JS, Beers DR, Siklós L, Appel SH (2006) The chemokine MCP-1 and 
the dendritic and myeloid cells it attracts are increased in the mSOD1 mouse model of ALS. Mol Cell Neurosci 31:427-437.

Kaindl AM, Guenther UP, Rudnik-Schöneborn S, Varon R, Zerres K, Schuelke M, Hübner C, von Au K (2008) Spinal muscular atrophy with respiratory distress type 1 (SMARD1). J Child Neurol 23:199-204.

Li M, Ona VO, Guégan C, Chen M, Jackson-Lewis V, Andrews LJ, Olszewski AJ, Stieg PE, Lee JP, Przedborski S, Friedlander RM (2000) Functional role of caspase- 1 and caspase- 3 in an ALS transgenic mouse model. Science 288:335-339.

Locatelli F, Corti S, Papadimitriou D, Fortunato F, Del Bo R, Donadoni C, Nizzardo M, Nardini M, Salani S, Ghezzi S, Strazzer S, Bresolin N, Comi GP (2007) Fas small interfering RNA reduces motor neuron death in amyotrophic lateral sclerosis mice. Ann Neurol 62:81-92.

Maddatu TP, Garvey SM, Shroeder DG, Hampton TG, Cox GA (2004) Transgenic rescue of neurogenic atrophy in the nmd mouse reveals a role for Ighmbp2 in dilated cardiomyopathy. Hum Mol Genet 13:1105-1115.
Mellins RB, Hays AP, Gold AP, Berdon WE, Bowdler JD (1974) Respiratory distress as the initial manifestation of Werdnig-Hoffmann disease. Pediatrics 53:33-40.

Messina A, Sangster CL, Morrison WA, Galea MP (2000) Requirements for obtaining unbiased estimates of neuronal numbers in frozen sections. J Neurosci Methods 97:133-137.

Molnar GM, Crozat A, Kraeft SK, Dou QP, Chen LB, Pardee AB (1997) Association of the mammalian helicase MAH with the pre-mRNA splicing complex. Proc Natl Acad Sci U S A 94:7831-7836.

Nguyen MD, Julien JP, Rivest S (2001) Induction of proinflammatory molecules in mice with amyotrophic lateral sclerosis: no requirement for proapoptotic interleukin-1beta in neurodegeneration. Ann Neurol 50:630-639.

Wichterle H, Lieberam I, Porter JA, Jessell TM (2002) Directed differentiation of embryonic stem cells into motor neurons. Cell 110:385-397.

Yan J, Xu L, Welsh AM, Hatfield G, Hazel T, Johe K, Koliatsos VE (2007) Extensive neuronal differentiation of human neural stem cell grafts in adult rat spinal cord. PLoS Med 4:e39. 